\title{
Theoretical Study on Relaxed Surrounding Rock Pressure on Shallow Bias Neighborhood Tunnels under Seismic Load
}

\author{
Xinrong Liu ${ }^{1,2,3}$, Fei Xiong ${ }^{1,2^{\star}}$, Dongshuang Liu ${ }^{1,2^{*}}$, Xiaohan Zhou $^{1,2,3}$, Dongliang Li ${ }^{4}$, Linfeng Wang ${ }^{1,2}$, \\ Yafeng Han ${ }^{1}$, Chunmei $\mathrm{He}^{5}$ \\ ${ }^{1}$ School of Civil Engineering, Chongqing University, Chongqing 400045, China \\ ${ }^{2}$ State Key Laboratory of Coal Mine Disaster Dynamics and Control, Chongqing University, Chongqing 400044, China \\ ${ }^{3}$ National Joint Engineering Research Center of Geohazards Prevention in The Reservoir Areas, Chongqing University, Chongqing \\ 400045, China \\ ${ }^{4}$ Chongqing Housing and Urban Rural Construction Commission, Chongqing 400010, China \\ ${ }^{5}$ College of Architectural Engineering, Neijiang Normal University, Neijiang 641100, China \\ * Corresponding author, e-mail:xiongfei@cqu.edu.cn; 332642300@qq.com
}

Received: 03 June 2021, Accepted: 26 July 2021, Published online: 16 August 2021

\begin{abstract}
To study the distribution of relaxed surrounding rock pressure on the shallow bias neighborhood tunnels under the combined action of horizontal and vertical earthquake force, finite element software was used for failure mode analysis. Moreover, with the pseudostatic method, the calculation formula for the relaxed pressure on the shallow bias neighborhood tunnels was derived and used to analyze the variation of the rupture angle of these tunnels under the action of the seismic force. The study shows that: shallow bias neighborhood tunnels basically follow a "W" failure pattern under the combined action of horizontal and vertical seismic force, and the failure scope of the surrounding rock is controlled by four rupture angles. Rupture angles $\beta_{2}$ and $\beta_{3}$ between the deep and shallow tunnels of the shallow bias neighborhood tunnels are not affected by the surface slope. For tunnels with the same grade of the surrounding rock, the greater the seismic intensity, the smaller the value of $\beta_{2}$, and the greater the value of $\beta_{3}$. While at the same seismic intensity, the higher the grade of the surrounding rock, the smaller the $\beta_{2}$ and $\beta_{3}$. Ruptures angles $\beta_{1}$ and $\beta_{4}$ are influenced by the surface slope, seismic intensity and surrounding rock grades. A steeper surface slope leads to a smaller $\beta_{1}$ and a greater $\beta_{4}$; $\beta_{1}$ increase and $\beta_{4}$ decrease with increasing seismic intensity; while, $\beta_{1}$ and $\beta_{4}$ both show a decreasing trend with an increasing rock grade.
\end{abstract}

\section{Keywords}

shallow, bias, tunnel, relaxed surrounding rock pressure, rupture angle

\section{Introduction}

A bias tunnel is under a biased load (asymmetric force). The development in highway tunnel construction demands the excavation of tunnels through mountain areas. The rugged landscape in those areas leads to the inevitable existence and rapid development of bias tunnels [1,2]. Due to their special form of load, bias tunnels are clearly distinguished from common tunnels in design and support [3-5]. For this reason, Yang et al. [6] conducted researches on the theoretical calculation of the rock pressure acting on three shallow tunnels subjected to unsymmetrical loads. Yang and Wang [7] analyzed the stress dilatancy of shallow tunnels subjected to unsymmetrical pressure. Lei et al. [8] investigated the failure mechanisms and lining stress characteristics of shallow buried tunnels under unsymmetrical loading. Liu et al. [9] examined the cracking mechanism of tunnel lining under bias pressure by experimental and numerical methods. The list goes on.

However, active crustal movement and reservoir filling has led to earthquake disasters from time to time [10-13]. People's demand for durability and safety of bias tunnels can no longer be satisfied merely through static analysis [14]. As a result, seismic design for these tunnels has become increasingly prominent. Sánchez-Merino et al. [15] researched the simple longitudinal seismic response of tunnel linings subject to surface wave. Wang et al. [16] investigated the seismic energy response and damage evolution of tunnel lining structures. Gomes [17] studied the effect of stress disturbance induced by construction on the seismic response of shallow bored tunnels. 
By reviewing relevant literature, it is known that previous researches on the seismic solution of tunnels focus on the effect of horizontal seismic force [18-20]. The same is true with existing specifications [21, 22]. However, in practice, the earthquake acceleration is a variable of great uncertainty in direction [23-25]. For example, a terrible earthquake struck Wenchuan County, Sichuan Province in 2008. Numerous buildings are damaged, in which the vertical seismic force also played a role [26]. Meanwhile, there has been a lack of systematic research in the area of bias neighborhood tunnels, which are more complicated than bias single tunnels.

Given the above, shallow bias neighborhood tunnels are studied considering the combined effect of horizontal and vertical seismic forces. With the pseudo-static method and the latest research results both in China and abroad, an analytical solution to the relaxed surrounding rock pressure of shallow bias neighborhood tunnels under seismic force action is derived. This solution is used for the analysis of the rupture angle of these tunnels.

\section{Failure Mode Analysis}

Surrounding rock pressure is the main load on the tunnel structure. According to the geological conditions and the structural features of the tunnel, surrounding rock pressure consists of relaxed pressure and deformation pressure [27]. According to incomplete statistics, shallow bias tunnels are usually built in steep mountain areas. Due to the poor geological conditions there, the surrounding rock of these tunnels is easily weathered. In the event of an earthquake, the weathered rock will invoke relaxed pressure, which requires close attention. At present, specifications and researches on the effect of horizontal and vertical seismic force together on shallow bias neighborhood tunnels are limited both at home and abroad.

To establish a calculation model for the structural load of shallow bias neighborhood tunnels subject to horizontal and vertical earthquake force, the loose zone and failure mode of the surrounding rock under earthquake forces shall be clearly defined. Through field investigation and acquired data (on the terrain, landform, and hydrogeological conditions) regarding some of the existing shallow bias neighborhood tunnels, a numerical model is established using finite element software. Based on this model, the distribution of the deformation and plastic zone of surrounding rock in limit equilibrium state under horizontal and vertical seismic load is analyzed with the Strength Reduction Finite Element Method.

To demonstrate the basic distribution pattern, the surrounding rock is treated as a homogeneous body, which is irrespective of the joint fissure and material type of the rock mass. The research is conducted under the most unfavorable conditions. That is, the seismic load is applied without secondary lining after the excavation is completed. The model features a viscous-spring artificial boundary, and the input seismic wave is an artificial seismic wave after a similar conversion.

Numerical analysis is made after the seismic wave of intensities VI, VII, and VIII (which are the most common) are applied to tunnels with different surface slopes and surrounding rock grades. The results show that the expansion of the plastic zone surrounding the tunnel follows a certain pattern. That is, the outer sidewall of the deep tunnel and the shallow tunnel is where stress is most concentrated. The plastic failure process begins here. It expands out and upward at a certain dip angle until it reaches the ground surface. Plastic zones also exist in the inner sidewall of the deep and shallow tunnels. Similarly,

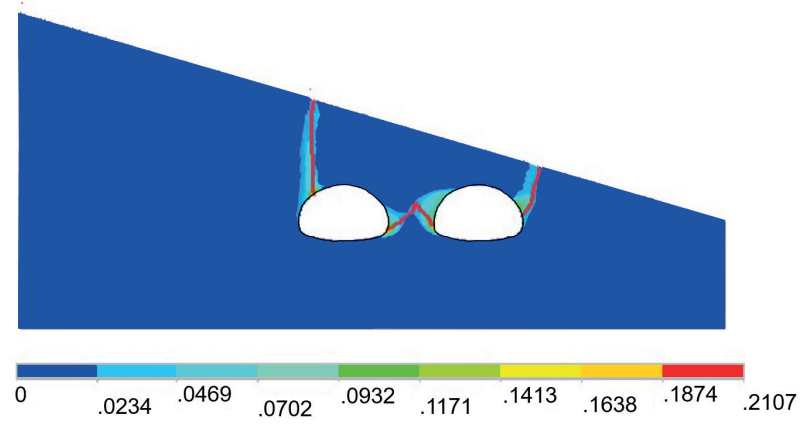

Fig. 1 The plastic strain of shallow bias neighborhood tunnel affected by the earthquake

Table 1 The physical and mechanical parameters of the model

\begin{tabular}{lcccc}
\hline & $\begin{array}{c}\text { Volume weight } \\
\gamma\left(\mathrm{kN} / \mathrm{m}^{3}\right)\end{array}$ & $\begin{array}{c}\text { Elastic modulus } \\
E(\mathrm{GPa})\end{array}$ & $\begin{array}{c}\text { Poisson ratio } \\
\mu\end{array}$ & $\begin{array}{c}\text { Cohesive } \\
c(\mathrm{MPa})\end{array}$ \\
\hline $\begin{array}{l}\text { Surrounding rock } \\
\text { Reinforcement } \\
\text { ring }\end{array}$ & 22 & 1.4 & 0.36 & 0.15 \\
Primary support & 23 & 1.6 & 0.33 & 21.0 \\
\hline
\end{tabular}


they expand upward at a certain dip angle and meet near the rock pillar in the middle. The whole plastic zone forms a connected shear plane in a "W" shape, as shown in Fig. 1 (The corresponding seismic wave intensity is VI, and the input model parameters are shown in Table 1). Meanwhile, at the upper part of the "W", where the rock mass is limited by the rupture angles of the tunnel, the surrounding rock has become loose and damaged.

Based on the analysis above, when horizontal and vertical seismic forces are applied simultaneously, the basic failure mode of the surrounding rock of shallow bias neighborhood tunnels can be concluded as follows: rupture planes develop in the outer sidewall of the deep and shallow tunnels and extend to the slope surface; sliding rupture planes develop in the sidewall between the left and right tunnels, extend obliquely upward and intersect near the middle rock pillar, following the shape of "W". The failure zone of the surrounding rock depends on the rupture angle at both sides of the tunnel. Based on this failure mode, a calculation model for the structural load of shallow bias neighborhood tunnels when subject to seismic load is established to ensure tunnel stability in the event of an earthquake.

\section{Pseudo-static Method}

There are a variety of ways in structural design and calculation of underground space. These ways fall into three categories: static method, pseudo-static method, and dynamic response analysis method [28]. Among them, the static method is over-simplistic, not accurate enough, and thus rarely used. Dynamic response analysis features high accuracy. However, it requires sophisticated expertise and skills. In addition, it is not easy to operate and evaluate the results. Therefore, designers tend to use the pseudo-static method for calculation, except for extremely significant projects or complicated geological conditions.

The pseudo-static method is simple and clear in concept, easy in the calculation, and widely used in engineering projects. Similar to the static method, it is an easy way to solve the problems in dynamics. The key point of this method is to apply constant inertia force in horizontal and vertical directions instead of seismic load on the structure under study. The direction of the inertia force is the most disadvantageous to the structure.

The horizontal and vertical inertia forces generated during an earthquake are as follows:

$F_{h}=\frac{\alpha_{h} G}{g}=k_{h} G$
$F_{v}=\frac{\alpha_{v} G}{g}=k_{v} G$,

where $\alpha_{h}$ and $\alpha_{v}$ are the horizontal and vertical pseudostatic accelerations, respectively.

$k_{h}$ is the pseudo-static acceleration factor in the horizontal direction. When the seismic intensity is VI, VII, and VIII, respectively, its value is $0.05,0.10$, and 0.20 .

$k_{v}$ is the pseudo-static acceleration factor in the vertical direction; it is determined by $\mathrm{kh}$ :

$k_{v}=(1 / 2 \sim 2 / 3) k_{h}$.

$G$ is the weight of rock-soil mass, and $g$ is the gravitational acceleration.

\section{Analytical solution to relaxed surrounding rock pressure}

\subsection{Basic assumptions}

Based on the characteristics of shallow bias neighborhood tunnels, the following assumptions are made to facilitate calculation:

(1) The rock-soil mass is an isotropic homogeneous continuous medium.

(2) Horizontal and vertical seismic load have no great influence on the basic physical and mechanical characteristics of rock-soil mass.

(3) Surface dip angle of the shallow bias neighborhood tunnel is $\alpha$. In the outer rock-soil mass of the deep tunnel, rupture plane $\mathrm{AI}$ develops and has a rupture angle $\beta_{1}$ to the horizontal plane; in the inner rock-soil mass, rupture plane $\mathrm{BN}$ develops and has a rupture angle $\beta_{2}$ to the horizontal plane. In the outer rock-soil mass of the shallow tunnel, rupture plane DQ develops and has a rupture angle $\beta_{4}$ to the horizontal plane; in the inner rock-soil mass, the rupture plane CL develops and has a rupture angle $\beta_{3}$ to the horizontal plane. In addition, $\mathrm{BN}$ and $\mathrm{CL}$ meet at $\mathrm{R}$ near the middle

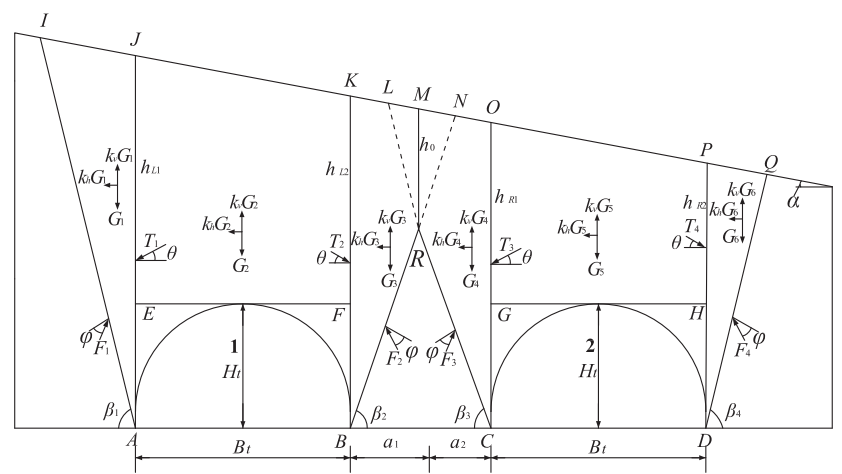

Fig. 2 Calculation diagram of surrounding rock pressure of shallow bias neighborhood tunnels under the seismic force 
rock pillar. As the tunnel is under unsymmetrical pressure, the point of intersection $\mathrm{R}$ deviates from the centerline of the middle rock pillar by a certain distance (see Fig. 2).

(4) When the overlaying rock-soil mass (EFKJ and GHPO) on the tunnel crown sinks, it drives the sinking of the rock-soil mass at both sides of the tunnel. However, when the whole rock-soil mass ADQI starts to sink, its downward movement is prevented by resistances from the unaffected rock-soil mass at both sides.

(5) Inclined planes AI, BR, CR and DQ are hypothetical sliding rupture planes. Their shear strength is determined by the cohesion (c) and the calculated friction angle $(\varphi)$ of rock-soil mass. The other flat planes $\mathrm{AJ}, \mathrm{BK}, \mathrm{CO}$, and $\mathrm{DP}$ are non-existent. They are hypothetical for easier analysis. Therefore, their sliding surface resistance is smaller than the resistance of a real rupture plane, and their friction angle $(\theta)$ is smaller than the calculated one $(\varphi)$.

In this paper, the relaxed surrounding rock pressure and rupture angle of shallow bias neighborhood tunnels considering the combined effect of horizontal and vertical seismic force are analyzed based on the assumptions above. Fig. 2 is a diagram for calculating surrounding rock pressure of shallow bias neighborhood tunnels under the action of a seismic force.

\subsection{The relaxed surrounding rock pressure of deep tunnel}

\subsubsection{Lateral horizontal pressure at the left side}

Surrounding rock AJI at the left side of the deep tunnel is selected for the study. Its force diagram is shown in Fig. 3. The weight of surrounding rock $G_{1}\left(\mathrm{kN} \cdot \mathrm{m}^{-1}\right)$ can be expressed as:

$$
\begin{aligned}
G_{1} & =\frac{1}{2} \gamma\left(H_{t}+h_{L 1}\right)^{2} \cdot \frac{\cos \alpha \cos \beta_{1}}{\sin \left(\beta_{1}-\alpha\right)} \\
& =\frac{1}{2} \gamma\left(H_{t}+h_{L 1}\right)^{2} \cdot \frac{\cos \alpha \cos \beta_{1}}{\sin \beta_{1} \cos \alpha-\cos \beta_{1} \sin \alpha} \\
& =\frac{1}{2} \gamma\left(H_{t}+h_{L 1}\right)^{2} \cdot \frac{1}{\tan \beta_{1}-\tan \alpha},
\end{aligned}
$$

where $\gamma\left(\mathrm{kN} \cdot \mathrm{m}^{-3}\right)$ is the volume weight of the surrounding rock.

In the event of an earthquake, AJI is affected by earthquake load. According to Eq. (1) and Eq. (2), inertia force will be generated in the horizontal $\left(k h G_{1}\right)$ and vertical $\left(k v G_{1}\right)$ directions of the rock-soil mass. See Fig. 4(a) for its force analysis. $T_{1}$ is the sliding force on plane $B C$ generated when AJI, driven by the sinking of the overlying rock-soil mass of the tunnel, slides; $F_{1}$ is the frictional resistance to AJI from the unaffected rock-soil mass.

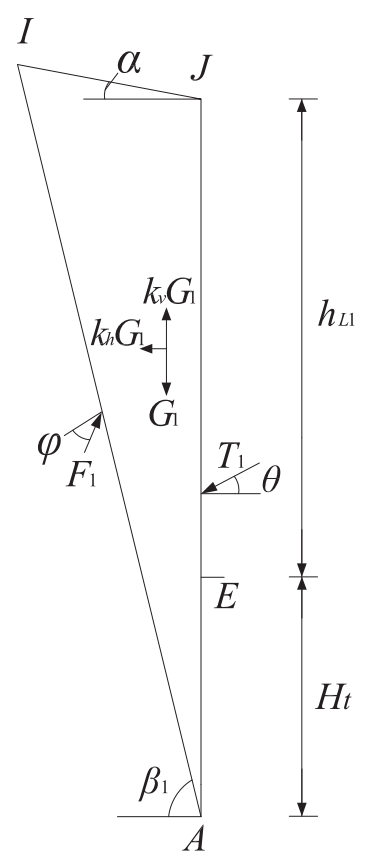

Fig. 3 Force calculation diagram of rock-soil mass AJI under the seismic force

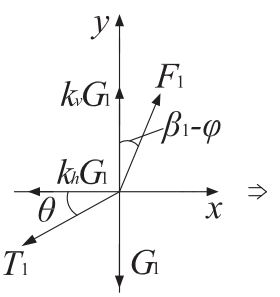

(a)

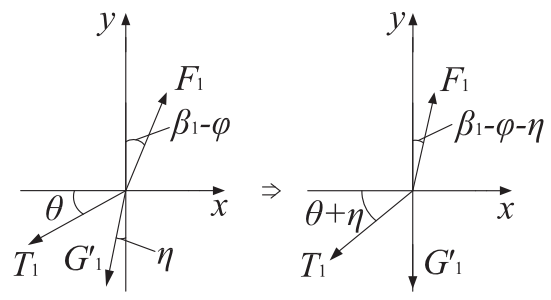

(b)

(c)
Fig. 4 Force analysis diagram of rock-soil mass AJI under the seismic force

In the pseudo-static method, the inertia forces $k h G_{1}$ and $k v G_{1}$ are seen as dead load and composed with $G_{1}$. The resultant force is $G_{1}{ }^{\prime}$. Where $\eta\left(^{\circ}\right)$ is the angle between $G_{1}{ }^{\prime}$ and the vertical direction, and $\eta$ is the seismic force deflection angle, as shown in Fig. 4(b).

$\eta=\arctan \left[k_{h} /\left(1-k_{v}\right)\right]$

It is easily known that

$G_{1}^{\prime}=\left(1-k_{v}\right) G_{1} \sec \eta$.

In order to convert the resultant force $G_{1}{ }^{\prime}$ to the vertical direction so that the calculation process is easier. Fig. 4(b) is rotated $\eta$ degrees counterclockwise, as shown in Fig. 4(c). The rotation does not change the equilibrium of the force system and geometrical relationship between forces, so the calculation results of the lateral horizontal pressure are not changed [22].

As shown in Fig. 4(c), the following is obtained from the equilibrium of forces: 
$\left\{\begin{array}{l}F_{1} \sin \left(\beta_{1}-\varphi-\eta\right)=T_{1} \cos (\theta+\eta) \\ F_{1} \cos \left(\beta_{1}-\varphi-\eta\right)=T_{1} \sin (\theta+\eta)+G_{1}^{\prime}\end{array}\right.$,

$T_{1}=\frac{G_{1}^{\prime} \tan \left(\beta_{1}-\varphi-\eta\right)}{\cos (\theta+\eta)-\sin (\theta+\eta) \tan \left(\beta_{1}-\varphi-\eta\right)}$.

According to the trigonometric function transformation formula, it is known that

$\tan \left(\beta_{1}-\varphi-\eta\right)=\frac{\tan \beta_{1}-\tan (\varphi+\eta)}{1+\tan \beta_{1} \tan (\varphi+\eta)}$.

By substituting Eqs. (4), (5) and (6) into Eq. (8), the following is obtained:

$T_{1}=\frac{1}{2} \gamma\left(H_{t}+h_{L 1}\right)^{2} \frac{1-k_{v}}{\cos (\theta+\eta) \cos \eta} \cdot \frac{1}{\tan \beta_{1}-\tan \alpha}$

$\cdot \frac{\tan \beta_{1}-\tan (\varphi+\eta)}{1+\tan \beta_{1}[\tan (\varphi+\eta)-\tan (\theta+\eta)]+\tan (\varphi+\eta) \tan (\theta+\eta)}$.

If $\lambda_{1}$ is the horizontal lateral pressure coefficient for the outer side of the deep tunnel, then

(11)

$\lambda_{1}=\frac{1-k_{v}}{\cos \eta} \cdot \frac{1}{\tan \beta_{1}-\tan \alpha}$

$\cdot \frac{\tan \beta_{1}-\tan (\varphi+\eta)}{1+\tan \beta_{1}[\tan (\varphi+\eta)-\tan (\theta+\eta)]+\tan (\varphi+\eta) \tan (\theta+\eta)}$.

Substitute Eq. (11) into Eq. (10), and the following is obtained:

$T_{1}=\frac{1}{2} \gamma\left(H_{t}+h_{L 1}\right)^{2} \cdot \frac{\lambda_{1}}{\cos (\theta+\eta)}$.

Based on Eq. (11), $\lambda_{1}$ is determined by $\eta, \varphi, \theta$, and $\beta_{1}$, where $\theta$ can be determined by $\varphi$. In general, all values but rupture angle $\beta_{1}$ are known. Thus, the value of sliding force $T_{1}$ changes only with $\beta_{1}$. $\beta_{1}$ is a hypothetical rupture angle, not a natural one in a limit state. The real rupture angle is most likely to exist in the position where $T_{1}$ reaches its maximum. Therefore, to get the real $\beta_{1}$, the maximum $T_{1}$ shall be obtained.

Let $d \lambda_{1} / d \tan \beta_{1}=0$, when $T_{1}$ reaches the maxima, the tangent value of the left rupture angle $\beta_{1}$ is as follows:

$\tan \beta_{1}=\tan (\varphi+\eta)$

$+\sqrt{\frac{\left[\tan ^{2}(\varphi+\eta)+1\right] \cdot[\tan (\varphi+\eta)-\tan \alpha]}{\tan (\varphi+\eta)-\tan (\theta+\eta)}}$,

where $\varphi$ is the calculated friction angle of plane AI, $\theta$ the friction angle of plane $\mathrm{AJ}$, and $\theta<\varphi . \theta$ can be determined by $\varphi$ [29]. It is evident that $\beta_{1}$ can be determined by $\varphi, \eta$, and $\alpha$.
According to the literature [29], the horizontal lateral pressure on the outer side of the deep tunnel is

$\left\{\begin{array}{l}e_{1}=\gamma h_{L 1} \lambda_{1} \\ e_{1}^{\prime}=\gamma\left(H_{t}+h_{L 1}\right) \lambda_{1}\end{array}\right.$

\subsubsection{Lateral horizontal pressure at the right side}

The rock-soil mass BRMK is selected for the study. $T_{2}$ is the sliding force on plane BK generated when BRMK, driven by the sinking of overlying rock mass of the tunnel, slides. $F_{2}$ is the frictional resistance on plane BR. $G_{3}$ is the weight of BRMK. Other loads and geometric parameters are shown in Fig. 5, and the force analysis is shown in Fig 6.

To facilitate calculation, rock-soil mass BRMK is seen as a trapezoid. Then

$G_{3}=\frac{1}{2} \gamma a_{1}\left(H_{t}+h_{L 2}+h_{0}\right)$.

In order for the resultant force $G_{3}{ }^{\prime}$ to be in the vertical direction so that calculation is easier. Fig. 6(b) is rotated $\eta$ degrees counterclockwise, as shown in Fig. 4(c).

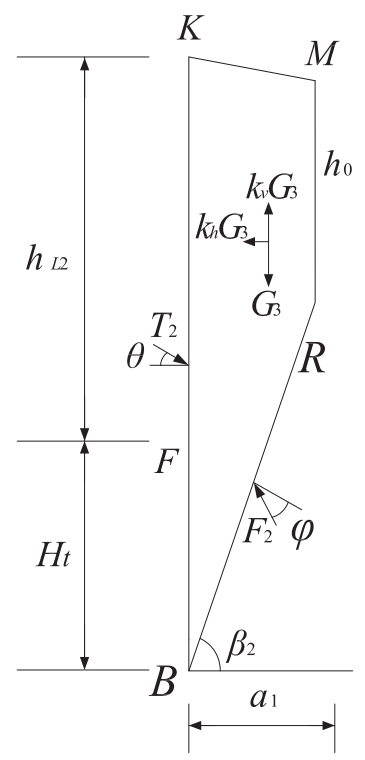

Fig. 5 Force calculation diagram of rock-soil mass BRMK under the seismic force

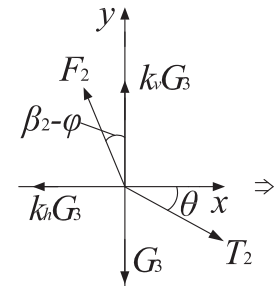

(a)

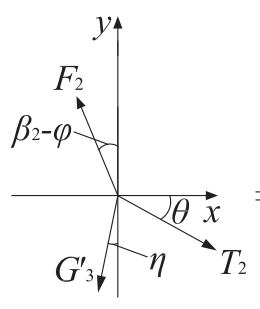

(b)

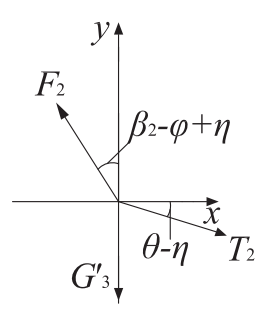

(c)
Fig. 6 Force analysis diagram of rock-soil mass BRMK under the seismic force 
In Fig. 6(c), the following can be obtained from the equilibrium of forces:

$$
\begin{aligned}
& \left\{\begin{array}{l}
F_{2} \sin \left(\beta_{2}-\varphi+\eta\right)=T_{2} \cos (\theta-\eta) \\
F_{2} \cos \left(\beta_{2}-\varphi+\eta\right)=T_{2} \sin (\theta-\eta)+G_{3}^{\prime},
\end{array}\right. \\
& G_{3}^{\prime}=\left(1-k_{v}\right) G_{3} \sec \eta, \\
& T_{2}=\frac{G_{3}^{\prime} \tan \left(\beta_{2}-\varphi+\eta\right)}{\cos (\theta-\eta)-\sin (\theta-\eta) \tan \left(\beta_{2}-\varphi+\eta\right)},
\end{aligned}
$$

$$
T_{2}=\frac{1}{2} \gamma a_{1}\left(H_{t}+h_{l 2}+h_{0}\right) \frac{1-k_{v}}{\cos (\theta-\eta) \cos \eta}
$$

$\cdot \frac{\tan \beta_{2}-\tan (\varphi-\eta)}{1+\tan \beta_{2}[\tan (\varphi-\eta)-\tan (\theta-\eta)]+\tan (\varphi-\eta) \tan (\theta-\eta)}$.

If $\lambda_{2}$ is the horizontal lateral pressure coefficient for the inner side of the deep tunnel, then

$\lambda_{2}=\frac{a_{1}\left(H_{t}+h_{L 2}+h_{0}\right)}{h_{L 2}^{2}} \cdot \frac{1-k_{v}}{\cos \eta}$.

$\frac{\tan \beta_{2}-\tan (\varphi-\eta)}{1+\tan \beta_{2}[\tan (\varphi-\eta)-\tan (\theta-\eta)]+\tan (\varphi-\eta) \tan (\theta-\eta)}$,

$T_{2}=\frac{1}{2} \gamma h_{L 2}^{2} \cdot \frac{\lambda_{2}}{\cos (\theta-\eta)}$.

From the geometrical relationship, it is known that, where $\mathrm{m}$ is the distance from $\mathrm{R}$ to $\mathrm{BC}$.

Similarly, let, so that $\mathrm{T} 2$ reaches its maximum, the following can be obtained:

$$
\begin{aligned}
& \tan \beta_{2}=\tan (\varphi-\eta) \\
& +\sqrt{\tan ^{2}(\varphi-\eta)+\frac{\tan (\varphi-\eta)[\tan (\varphi-\eta) \cdot \tan (\theta-\eta)+1]}{\tan (\varphi-\eta)-\tan (\theta-\eta)}} .
\end{aligned}
$$

Where $\varphi$ is the calculated friction angle of plane BR, $\theta$ the friction angle of plane BK and $\theta<\varphi . \theta$ can be determined by $\varphi$. It is known that $\beta_{2}$ can be determined by $\varphi$ and $\eta$. from Eq. (22), it is learned that the rupture angle $\left(\beta_{2}\right)$ between the deep and shallow tunnels, when subject to both horizontal and vertical seismic forces, are not affected by the topography and independent of the surface slope $(\alpha)$.

The horizontal lateral pressure on the inner side of the deep tunnel is:

$$
\left\{\begin{array}{l}
e_{2}=\gamma h_{L 2} \lambda_{2} \\
e_{2}^{\prime}=\gamma\left(H_{t}+h_{L 2}\right) \lambda_{2}
\end{array}\right.
$$

\subsubsection{Vertical surrounding rock pressure on the tunnel crown}

$\mathrm{AE}$ and $\mathrm{BF}$ are smaller than $\mathrm{EJ}$ and $\mathrm{FK}$, and their friction angles between the lining and soil are different. According to [29], EFKJ is selected as the overlying rock-soil mass of the tunnel crown.

For EFKJ, $G_{2}$ is its weight, and $T_{1}$ and $T_{2}$ are the same as above. $Q_{L}$ is the gross counterforce of the deep tunnel crown on EFKJ. Its value equals the gross vertical pressure of EFKJ on the crown. Parameters of EFKJ under the action of horizontal and vertical seismic force are shown in Fig. 7.

It can be easily known that

$G_{2}=\frac{1}{2} \gamma B_{t}\left(h_{L 1}+h_{L 2}\right)$.

As $\sum Y=0$, it is obtained that

$Q_{L}=\left(1-k_{v}\right) G_{2}-T_{1} \sin \theta-T_{2} \sin \theta$.

By substituting Eqs. (12), (21) and (24) into Eq. (25), the following is obtained:

$Q_{L}=\frac{1}{2} \gamma\left[\begin{array}{l}B_{t}\left(1-k_{v}\right) \cdot\left(h_{L 1}+h_{L 2}\right) \\ -\frac{\lambda_{1}\left(H_{\mathrm{t}}+\mathrm{h}_{L 1}\right)^{2}}{\cos (\theta+\eta)}-\frac{\lambda_{2} h_{L 2}^{2}}{\cos (\theta-\eta)}\end{array}\right]$.

Assuming that the distribution of bias pressure follows the same pattern with the surface slope, $Q_{L}$ can be converted into the uniform load on the supporting structure of the left tunnel crown:

$q_{L}=\frac{1}{2} \gamma\left[\begin{array}{l}\left(1-k_{v}\right) \cdot\left(h_{L 1}+h_{L 2}\right) \\ -\frac{\lambda_{1}\left(H_{t}+h_{L 1}\right)^{2}}{B_{t} \cos (\theta+\eta)}-\frac{\lambda_{2} h_{L 2}^{2}}{B_{t} \cos (\theta-\eta)}\end{array}\right]$.

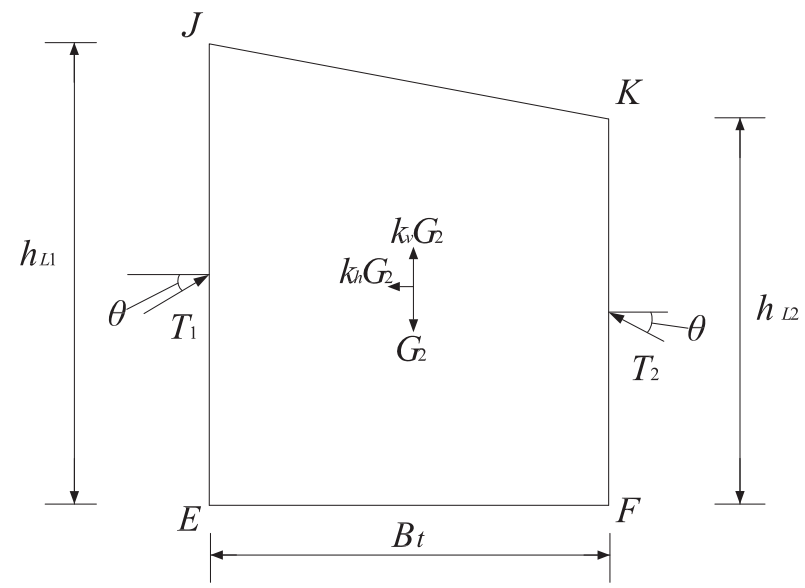

Fig. 7 Force calculation diagram of EFKJ under the seismic force 
Let the vertical pressure of EFKJ on the EJ side of the tunnel be $q_{1}$, and that on the FK side be $q_{2}$. As is known, the rock-soil mass pressure changes linearly. So:

$\left\{\begin{array}{l}q_{1}=q_{L}+\frac{B_{t}}{2} \tan \alpha \\ q_{2}=q_{L}-\frac{B_{t}}{2} \tan \alpha\end{array}\right.$.

The same analysis procedure applies to the shallow tunnel. Therefore, the following can be obtained.

\subsection{The relaxed surrounding rock pressure of shallow tunnel}

4.3.1 Lateral horizontal pressure at the left side

The Force calculation diagram of rock-soil mass COMR under seismic force is shown in Fig. 8. The unit weight of rock-soil mass COMR can be approximately expressed as follows:

$$
\begin{aligned}
G_{4} & =\frac{1}{2} \gamma a_{2}\left(H_{t}+h_{R 1}+h_{0}\right), \\
T_{3} & =\frac{G_{4}^{\prime} \tan \left(\beta_{3}-\varphi-\eta\right)}{\cos (\theta+\eta)-\sin (\theta+\eta) \tan \left(\beta_{3}-\varphi-\eta\right)} \\
& =\frac{1}{2} \gamma h_{R 1}^{2} \cdot \frac{\lambda_{3}}{\cos (\theta+\eta)} .
\end{aligned}
$$

The horizontal lateral pressure coefficient for the inner side of the shallow tunnel $\lambda_{3}$ :

$\lambda_{3}=\frac{a_{2}\left(H_{t}+h_{R 1}+h_{0}\right)}{h_{R 1}^{2}} \cdot \frac{1-k_{v}}{\cos \eta}$

$\cdot \frac{\tan \beta_{3}-\tan (\varphi+\eta)}{1+\tan \beta_{3}[\tan (\varphi+\eta)-\tan (\theta+\eta)]+\tan (\varphi+\eta) \tan (\theta+\eta)}$.

Where $a_{2}=m / \tan \beta_{3}$ and $m$ is the distance between $\mathrm{R}$ and $\mathrm{BC}$.

Tangent value of the rupture angle $\beta_{3}$ :

$$
\begin{aligned}
& \tan \beta_{3}=\tan (\varphi+\eta) \\
& +\sqrt{\tan ^{2}(\varphi+\eta)+\frac{\tan (\varphi+\eta)[\tan (\varphi+\eta) \cdot \tan (\theta+\eta)+1]}{\tan (\varphi+\eta)-\tan (\theta+\eta)}} .
\end{aligned}
$$

According to Eq. (32), when subject to both horizontal and vertical seismic forces, the rupture angle $\left(\beta_{3}\right)$ between the deep and shallow tunnels, is not affected by the topography and is independent of the surface slope $(\alpha)$.

The horizontal lateral pressure on the inner side of the shallow tunnel is: $\left\{\begin{array}{l}e_{3}=\gamma h_{R 1} \lambda_{3} \\ e_{3}^{\prime}=\gamma\left(H_{t}+h_{R 1}\right) \lambda_{3}\end{array}\right.$.

\subsubsection{Lateral horizontal pressure at the right side}

The force calculation diagram of rock-soil mass DQP under seismic force is given in Fig. 9.

$$
G_{6}=\frac{1}{2} \gamma\left(H_{t}+h_{R 2}\right)^{2} \cdot \frac{\cos \alpha \cos \beta_{4}}{\sin \left(\alpha+\beta_{4}\right)}
$$

$$
\begin{aligned}
T_{4} & =\frac{G_{6}^{\prime} \tan \left(\beta_{6}-\varphi+\eta\right)}{\cos (\theta-\eta)-\sin (\theta-\eta) \tan \left(\beta_{6}-\varphi+\eta\right)} \\
& =\frac{1}{2} \gamma\left(H_{t}+h_{R 2}\right)^{2} \cdot \frac{\lambda_{4}}{\cos (\theta-\eta)}
\end{aligned}
$$

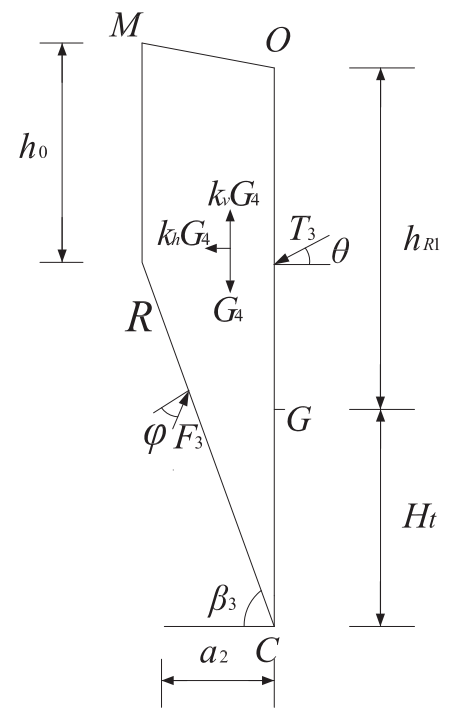

Fig. 8 Force calculation diagram of rock-soil mass COMR under the seismic force

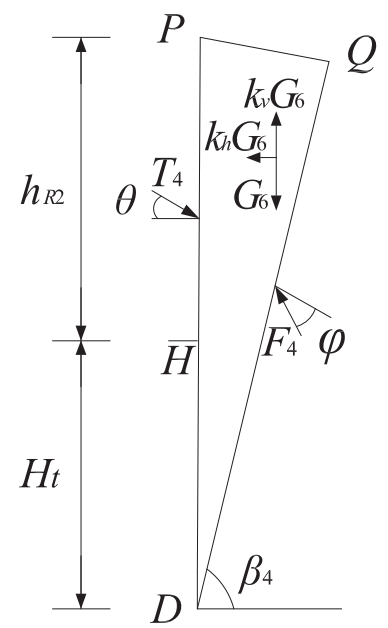

Fig. 9 Force calculation diagram of rock-soil mass DQP under the seismic force 
The horizontal lateral pressure coefficient for the outer side of the shallow tunnel $-\lambda_{4}$ :

$\lambda_{4}=\frac{1-k_{v}}{\cos \eta} \cdot \frac{1}{\tan \alpha+\tan \beta_{4}}$

$\cdot \frac{\tan \beta_{4}-\tan (\varphi-\eta)}{1+\tan \beta_{4}[\tan (\varphi-\eta)-\tan (\theta-\eta)]+\tan (\varphi-\eta) \tan (\theta-\eta)}$.

Tangent value of the rupture angle $\beta_{4}$ :

$\tan \beta_{4}=\tan (\varphi-\eta)$

$$
+\sqrt{\frac{\left[\tan ^{2}(\varphi-\eta)+1\right] \cdot[\tan (\varphi-\eta)+\tan \alpha]}{\tan (\varphi-\eta)-\tan (\theta-\eta)}} .
$$

The horizontal lateral pressure on the outer side is:

$\left\{\begin{array}{l}e_{4}=\gamma h_{R 2} \lambda_{4} \\ e_{4}^{\prime}=\gamma\left(H_{t}+h_{R 2}\right) \lambda_{4}\end{array}\right.$

\subsubsection{Vertical surrounding rock pressure on the tunnel crown}

The Force calculation diagram of GHPO under seismic force is given in Fig. 10. Assuming the distribution of bias pressure follows the same pattern with the surface slope, the uniform load on the supporting structure of the shallow tunnel crown is:

$q_{R}=\frac{1}{2} \gamma\left[\begin{array}{l}\left(1-k_{v}\right) \cdot\left(h_{R 1}+h_{R 2}\right) \\ -\frac{\lambda_{3} h_{R 1}^{2}}{B_{t} \cos (\theta+\eta)}-\frac{\lambda_{4}\left(H_{t}+h_{R 2}\right)^{2}}{B_{t} \cos (\theta-\eta)}\end{array}\right]$.

Let the vertical pressure of GHPO on the CG side be $q_{3}$, and that on the $\mathrm{DH}$ side be $q_{4}$. According to the literature [29], the rock-soil mass pressure changes linearly. So:

$\left\{\begin{array}{l}q_{3}=q_{R}+\frac{B_{t}}{2} \tan \alpha \\ q_{4}=q_{R}-\frac{B_{t}}{2} \tan \alpha\end{array}\right.$.

Based on the analysis above, the distribution of surrounding rock pressure on shallow bias neighborhood tunnels subject to both horizontal and vertical seismic forces is obtained, as shown in Fig. 11.

\section{Project case}

\subsection{Project overview}

Located in Shanxi Province, China, Zhangjialing Tunnel is a typical shallow bias neighborhood tunnel, as shown in
Fig. 12. The tunnel site is in a hilly loess region featured by loess hillocks, about 1025.7-1163.9 $\mathrm{m}$ in altitude and $138.2 \mathrm{~m}$ in height difference. The tunnel runs across the loess mountain ridge area, nearly E-W with loess gullies, valleys, and slopes at both sides. The vegetation is mainly wasteland shrub distributed along the gullies. At the upper part of hills and the gentle slopes are arable lands. Both the left and right tunnels are medium-length tunnels. The distance between the adjacent sides of the two tunnels is $9.2-12.8 \mathrm{~m}$. The tunnel generally stretches in the direction

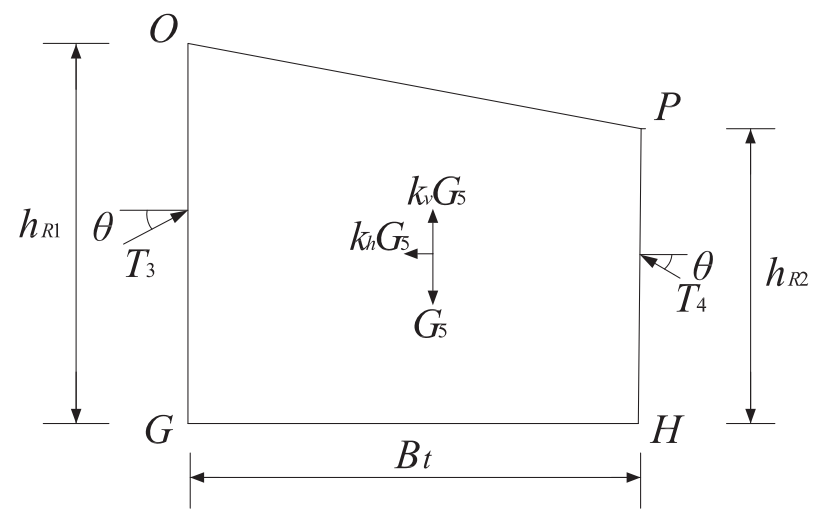

Fig. 10 Force calculation diagram of GHPO under the seismic force

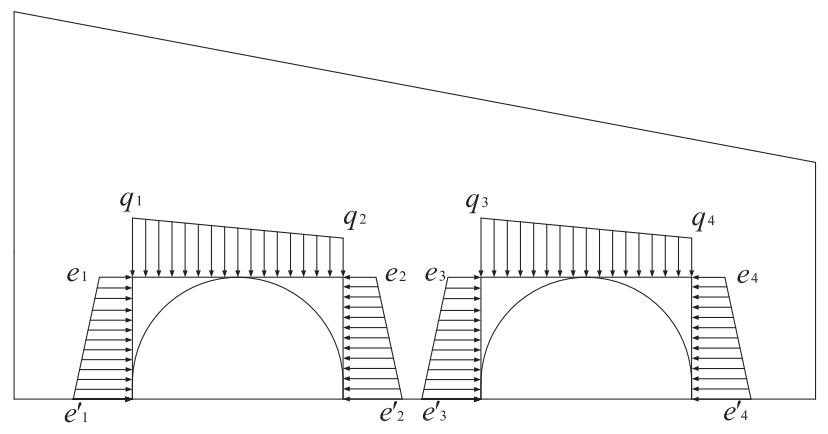

Fig. 11 Distribution of surrounding rock pressure on shallow bias neighborhood tunnels under the seismic force

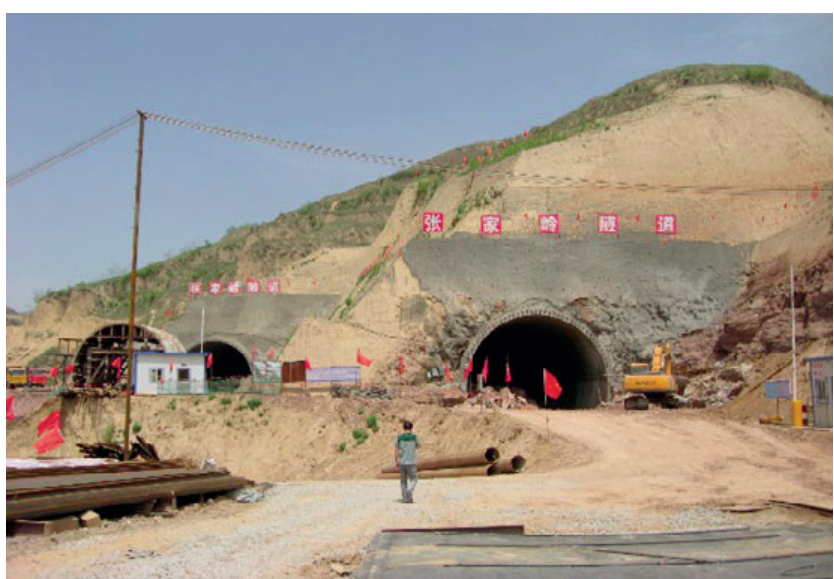

Fig. 12 Zhangjialing Tunnel 
of $206^{\circ}$. Designed with the New Austrian Tunneling Method (NATM), the tunnel body lining is a composite lining consisting of primary support, a secondary lining, and a waterproof layer between them. The primary support is anchor bolt support, made up of shotcrete, anchor bolt, mesh reinforcement or steel frame, or any combination of them. The secondary lining is a form of working reinforced concrete structure with an equal-depth section. Meanwhile, auxiliary structures such as long pipe roof, short pipe roof, and advance anchor bolt are added according to the stratum and geological conditions. For the shallow bias tunnel, the surrounding rock is of Grade V, with a volume weight of $17.6 \mathrm{kN} / \mathrm{m}^{3}$. A cross-section is selected for analysis. In the cross-section, the deep tunnel is $29.20 \mathrm{~m}$ in buried depth, the shallow tunnel is $18.24 \mathrm{~m}$ in buried depth, and the clear distance between them is $13.6 \mathrm{~m}$. Every single tunnel is $12.50 \mathrm{~m}$ in excavation width and $10.10 \mathrm{~m}$ in height. Their surface dip angle is $22.8^{\circ}$.

\subsection{Field monitoring on contact pressure between a surrounding rock and primary support}

In order to monitor the surrounding rock pressure, a group of monitoring points is arranged in a cross-section. See Fig. 13 for the arrangement.

\subsection{Field monitoring vs. theoretical calculation}

The vertical and the lateral horizontal relaxed surrounding rock pressure values can be determined by Eqs. (14), (23), (28), (33), (38), and (40). See Fig. 14.

During the excavation, the tunnel location was hit by a VI-intensity earthquake, followed by several aftershocks. The surrounding rock pressure gauge detected the pressure change during the earthquake. For easier comparison between the theoretical values and the field monitoring values, the vertical and the lateral horizontal surrounding rock pressures in Fig. 14 are combined. And their resultant vector is applied to the tunnel. The theoretical and monitored values of each monitoring point are organized and shown in Table 2.

From this table, it is found that the monitored values of each point are smaller than the theoretical values. This happens for two reasons. First, field monitoring points are arranged after excavation has been started. At this time, part of the surrounding rock pressure has been released, and the released amount is not measurable. Second, the theoretical calculation is based on a series of assumptions and the limit equilibrium theory, while in actual tunnel works, it is impossible for surrounding rock deformation to fully develop and even come into failure. Monitored values follow a similar distribution pattern and are smaller than theoretical ones. That is to say, theoretical values involve a certain safety margin. Therefore, the use of this theoretical model to calculate the surrounding rock pressure of the tunnel under the action of the seismic load is safe and feasible.

\section{Rupture Angle Sensitivity Analysis}

In China's specifications on tunnel engineering, surrounding rocks are classified into Grade I through VI. Among them, Grade I, II, and VI are virtually nonexistent in real projects. Therefore, the more common Grade III, IV, and V surrounding rocks are selected for discussion. According to [29], geotechnical parameters for the surrounding rock of each grade are shown in Table 3.

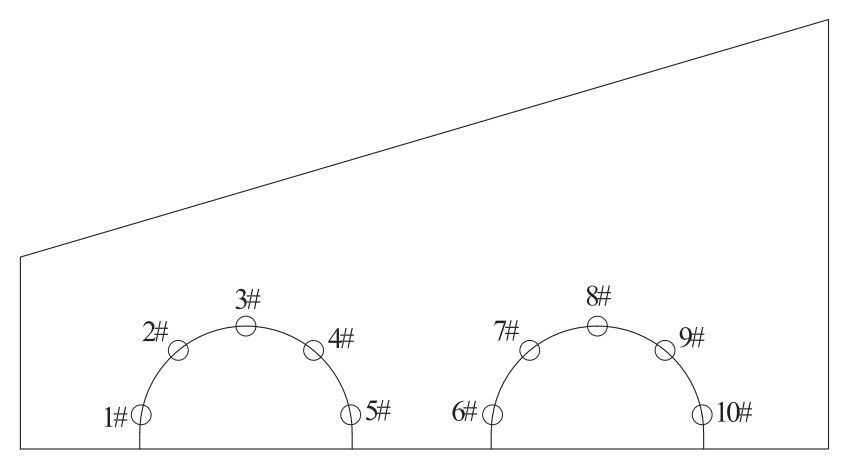

Fig. 13 Arrangement of monitoring points

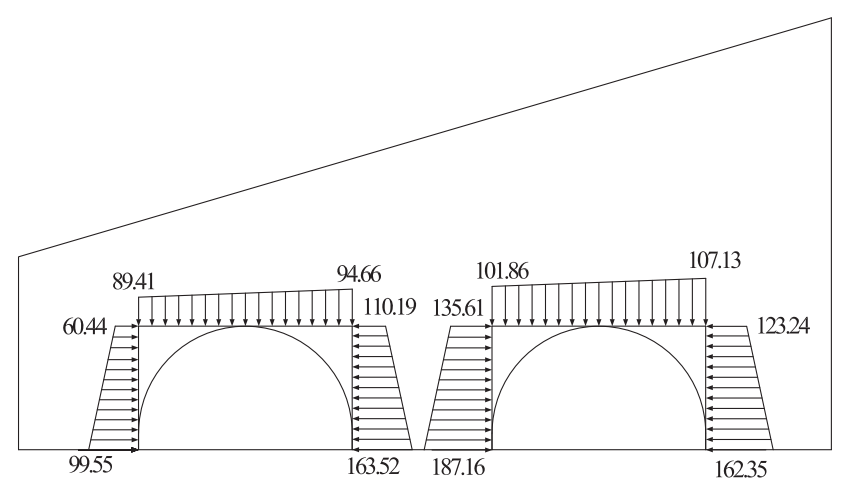

Fig. 14 Theoretical values of surrounding rock pressure of Zhangjialing Tunnel $(\mathrm{kPa})$

Table 2 Theoretical and monitored values of surrounding rock pressure $(\mathrm{kPa})$

\begin{tabular}{lccccccccccccc}
\hline Monitoring points & $1 \#$ & $2 \#$ & $3 \#$ & $4 \#$ & $5 \#$ & $6 \#$ & $7 \#$ & $8 \#$ & $9 \#$ & $10 \#$ \\
\hline Theoretical values & 126.13 & 114.61 & 92.03 & 157.24 & 177.38 & 201.47 & 184.51 & 104.50 & 173.66 & 183.86 \\
Monitoring values & 108.43 & 101.32 & 84.98 & 138.98 & 161.22 & 180.83 & 165.29 & 89.23 & 158.92 & 165.29 \\
\hline
\end{tabular}


Table 3 Geotechnical parameters of surrounding rock

\begin{tabular}{lccc}
\hline Rock classification & III & IV & V \\
\hline$\varphi\left({ }^{\circ}\right)$ & 65.0 & 55.0 & 45.0 \\
\hline$\theta\left({ }^{\circ}\right)$ & 58.5 & 44.0 & 27.0 \\
\hline
\end{tabular}

When the seismic intensity is VI, VII, and VIII, respectively, the horizontal seismic acceleration coefficient is $0.05,0.10$, and 0.20 . Assuming that the maximum of the vertical seismic acceleration coefficient, i.e., $k_{v}=0.67 k_{h}$, is taken for study. According to Eq. (5), it can be obtained that the seismic force-deflection angle $\eta$ is $3.0^{\circ}, 6.1^{\circ}$, and $13.0^{\circ}$, respectively. According to Eq. (22), Eq. (32), and Table 3 , the rupture angles $\beta_{2}$ and $\beta_{3}$ when the twin tunnels are under different surrounding rock conditions, and seismic fortification intensities can be obtained (see Table 4).

It can be found that for the shallow bias neighborhood tunnel under seismic load when surrounding rock grade is the same, the greater the seismic intensity, the smaller the value of $\beta_{2}$, and the greater the value of $\beta_{3}$. For example, when the surrounding rock is of Grade III, the value of $\beta_{2}$ drops from 81.1 to 80.3 to $78.4^{\circ}$, while the value of $\beta_{3}$ increases from 82.6 to 83.5 to $85.5^{\circ}$. Moreover, at the same seismic intensity, the values of $\beta_{2}$ and $\beta_{3}$ decrease with the increase of the grade of surrounding rock. For example, when the seismic intensity is VI, the values of $\beta_{2}$ $\left(\beta_{3}\right)$ decrease from $81.1(82.6)$ to $70.4^{\circ}\left(73.0^{\circ}\right)$ with the rock grade varying from III to $\mathrm{V}$.
For shallow bias neighborhood tunnels with a surrounding rock of Grade III, IV, or V, values of $\beta_{1}$ and $\beta_{4}$ under different seismic fortification intensities when the surface slope changes from $15^{\circ}-45^{\circ}$ can be obtained from Eq. (13), Eq. (37), and Table 3. See Table 5.

Data in Table 5 show that surface slope has a significant influence on the values of $\beta_{1}$ and $\beta_{4}$. When the surrounding rock grade and seismic intensity are constant, $\beta_{1}$ decreases, and $\beta_{4}$ increases with the increase of surface slope. For example, for a shallow bias neighborhood tunnel with a surrounding rock of Grade IV, when the seismic fortification intensity is VII and the surface slope increases from $15^{\circ}$ to $30^{\circ}$ and to $45^{\circ}$, the value of $\beta_{1}$ is $78.9^{\circ}, 78.1^{\circ}$ and $76.6^{\circ}$ (decreasing) respectively, and the value of $\beta_{4}$ is $76.4^{\circ}, 77.3^{\circ}$ and $78.3^{\circ}$ (increasing) respectively. It is also noted that when the seismic intensity is VIII and the surrounding rock grade is fixed, with the change of surface slope, $\beta_{1}$ and $\beta_{4}$ follow the same variation trend as stated above, but by a much smaller amount than in other cases. When surrounding rock grade and surface slope are constant, $\beta_{1}$ increase and $\beta_{4}$ decrease with increasing seismic intensity. For example, for a shallow bias neighborhood tunnel with a surrounding rock of Grade III, when the surface slope is $15^{\circ}$ and the seismic intensity increases from VI to VIII, the value of $\beta_{1}$ increase from 82.4 to $85.4^{\circ}$, while the value of $\beta_{4}$ decrease from 81.5 to $79.2^{\circ}$. While, as the surface slope and seismic intensity are constant,

Table 4 Calculated values of $\beta_{2}$ and $\beta_{3}$

\begin{tabular}{lcccccc}
\hline Seismic intensity & VI & VII & VIII & VI & VII & VIII \\
\hline Rock classification & & $\beta_{2}\left(^{\circ}\right)$ & & & $\beta_{3}\left({ }^{\circ}\right)$ & \\
III & 81.1 & 80.3 & 78.4 & 82.6 & 83.5 & 85.5 \\
IV & 76.5 & 75.4 & 72.8 & 78.4 & 79.4 & 81.7 \\
V & 70.4 & 68.8 & 65.0 & 73.0 & 74.3 & 77.0 \\
\hline
\end{tabular}

Table 5 Calculated values of $\beta_{1}$ and $\beta_{4}$

\begin{tabular}{|c|c|c|c|c|c|c|c|}
\hline \multirow{2}{*}{ Rock classification } & \multirow{2}{*}{$\begin{array}{c}\text { Seismic intensity } \\
\text { Slope } \\
\end{array}$} & VI & VII & VIII & VI & VII & VIII \\
\hline & & \multicolumn{3}{|c|}{$\beta_{1}\left({ }^{\circ}\right)$} & \multicolumn{3}{|c|}{$\beta_{4}\left({ }^{\circ}\right)$} \\
\hline \multirow{3}{*}{ III } & $15^{\circ}$ & 82.4 & 83.3 & 85.4 & 81.5 & 80.8 & 79.2 \\
\hline & $30^{\circ}$ & 82.0 & 83.0 & 85.3 & 81.9 & 81.2 & 79.9 \\
\hline & $45^{\circ}$ & 81.3 & 82.6 & 85.1 & 82.4 & 81.8 & 80.7 \\
\hline \multirow{3}{*}{ IV } & $15^{\circ}$ & 77.7 & 78.9 & 81.4 & 77.3 & 76.4 & 74.3 \\
\hline & $30^{\circ}$ & 76.7 & 78.1 & 81.0 & 78.1 & 77.3 & 75.6 \\
\hline & $45^{\circ}$ & 74.5 & 76.6 & 80.3 & 78.9 & 78.3 & 76.9 \\
\hline \multirow{3}{*}{ V } & $15^{\circ}$ & 71.5 & 73.1 & 76.3 & 71.9 & 70.6 & 67.7 \\
\hline & $30^{\circ}$ & 69.0 & 71.1 & 75.2 & 73.3 & 72.2 & 69.9 \\
\hline & $45^{\circ}$ & 60.8 & 66.1 & 73.0 & 74.7 & 73.8 & 72.0 \\
\hline
\end{tabular}


$\beta_{1}$ and $\beta_{4}$ both show a decreasing trend with an increasing rock grade. For instance, the values of $\beta_{1}\left(\beta_{4}\right)$ decrease from $82.4(81.5)$ to $77.7(77.3)$ to $71.5^{\circ}\left(71.9^{\circ}\right)$ with rock grade varying from III to $\mathrm{V}$ when the surface slope is $15^{\circ}$ and the seismic intensity is VI.

\section{Conclusions}

(1) Under the combined effect of horizontal and vertical seismic force, the basic failure mode of the surrounding rock of a shallow bias neighborhood tunnel is as follows: obliquely upward rupture planes develop in the outer sidewall of the deep and shallow tunnels and extend to the slope surface; obliquely upward sliding rupture planes develop in the sidewall between the deep and shallow tunnels, and intersect near the middle rock pillar, following the shape of "W". The failure zone of the surrounding rock depends on the four rupture angles.

(2) Based on the conclusion (1), the calculation formula of surrounding rock pressure and rupture angles of the shallow bias neighborhood tunnel subject to both horizontal and vertical seismic force is obtained.

(3) Ruptures angles $\beta_{2}$ and $\beta_{3}$ between the deep and shallow tunnels of the shallow bias neighborhood tunnel are independent of the surface slope and topographic

\section{References}

[1] Lei, M., Peng, L., Shi, C., Xie, Y., Tan, L. "Upper bound analytical solution for surrounding rock pressure of shallow unsymmetrical loading tunnels", Journal of Central South University, 22(6), pp. 2339-2347, 2015.

https://doi.org/10.1007/s11771-015-2759-4

[2] Xiao, J. Z., Dai, F. C., Wei, Y. Q., Xing, Y. C., Cai, H., Xu, C. "Analysis of mechanical behavior in a pipe roof during excavation of a shallow bias tunnel in loose deposits", Environmental Earth Sciences, 75(4), Article number: 293, 2016.

https://doi.org/10.1007/s12665-015-5176-y

[3] Lei, M., Lin, D., Yang, W., Shi, C., Peng, L., Huang, J. "Model test to investigate failure mechanism and loading characteristics of shallow-bias tunnels with small clear distance", Journal of Central South University, 23(12), pp. 3312-3321, 2016. https://doi.org/10.1007/s11771-016-3397-1

[4] Mohtadinia, M., Ahmadi, M. H., Fasaghandis, M. M., Dibavar, B. H., Davarpanah, S. M. "Statistical and numerical study of chipping and cracking in segmental lining", Periodica Polytechnica Civil Engineering, 64(3), pp. 869-886, 2020.

https://doi.org/10.3311/PPci.16037

[5] Zhang, T., Nie, L., Zhang, M., Dai, S., Xu, Y., Du, C., Rui, X., He, Y. "The Unsymmetrical Coefficient of Unsymmetrical-Loaded Tunnel Based on Field Monitoring and Numerical Simulation", Symmetry, 12(11), Article number: 1793, 2020. https://doi.org/10.3390/sym12111793 relief. For tunnels with the same grade of the surrounding rock, the higher the seismic intensity, the smaller the value of $\beta_{2}$, and the greater the value of $\beta_{3}$. At the same seismic intensity, the higher the surrounding rock grade, the smaller the values of $\beta_{2}$ and $\beta_{3}$.

(4) Ruptures angles $\beta_{1}$ and $\beta_{4}$ are influenced by the surface slope, seismic intensity and surrounding rock grades. When the surrounding rock grade and seismic intensity are constant, a steeper surface slope leads to a smaller $\beta_{1}$ and a greater $\beta_{4}$. When the surrounding rock grade and surface slope are constant, $\beta_{1}$ increase and $\beta_{4}$ decrease with increasing seismic intensity. While, as the surface slope and seismic intensity are constant, $\beta_{1}$ and $\beta_{4}$ both show a decreasing trend with an increasing rock grade.

\section{Acknowledgments}

This research was supported by the National Key R\&D Program of China (Grant No. 2018YFC1504802), National Natural Science Foundation of China (Grant No. 41972266) and the Graduate Research and Innovation Foundation of Chongqing, China (Grant No. CYS21029).

[6] Yang, X., Zhang, J., Jin, Q., Ma, J. "Analytical solution to rock pressure acting on three shallow tunnels subjected to unsymmetrical loads", Journal of Central South University, 20(2), pp. 528-535, 2013.

https://doi.org/10.1007/s11771-013-1515-X

[7] Yang, X., Wang, J. "Stress dilatancy analysis of shallow tunnels subjected to unsymmetrical pressure", Journal of Central South University of Technology, 15, pp. 28-33, 2008. https://oi.org/10.1007/s11771-008-0431-y

[8] Lei, M., Peng, L., Shi, C. "Model test to investigate the failure mechanisms and lining stress characteristics of shallow buried tunnels under unsymmetrical loading", Tunnelling and Underground Space Technology, 46, pp. 64-75, 2015. https://doi.org/10.1016/j.tust.2014.11.003

[9] Liu, D., Li, M., Zuo, J., Gao, Y., Zhong, F., Zhang, Y., Chang, Y. "Experimental and numerical investigation on cracking mechanism of tunnel lining under bias pressure", Thin-Walled Structures, 163, Article number: 107693, 2021. https://doi.org/10.1016/j.tws.2021.107693

[10] Feng, G.-L., Feng, X.-T., Chen, B.-R., Xiao, Y.-X., Liu, G.-F., Zhang, W., Hu, L. "Characteristics of Microseismicity during Breakthrough in Deep Tunnels: Case Study of Jinping-II Hydropower Station in China", International Journal of Geomechanics, 20(2), Article number: $04019163,2020$.

https://doi.org/10.1061/(Asce)GM.1943-5622.0001574 
[11] Kampas, G., Knappett, J. A., Brown, M. J., Anastasopoulos, I., Nikitas, N., Fuentes, R. "Implications of volume loss on the seismic response of tunnels in coarse-grained soils", Tunnelling and Underground Space Technology, 95, Article number: 103127, 2020. https://doi.org/10.1016/j.tust.2019.103127

[12] Oliaei, M., Basirat, R. "The Effect of Earthquake Frequency Content on the Internal Forces in the Tunnels Permanent Lining", Journal of Earthquake Engineering, 2019. https://doi.org/10.1080/13632469.2019.1693445

[13] Xiao, P., Li, T., Xu, N., Zhou, Z., Liu, X. "Microseismic monitoring and deformation early warning of the underground caverns of Lianghekou hydropower station, Southwest China", Arabian Journal of Geosciences, 12(16), Article number: 496, 2019. https://doi.org/10.1007/s12517-019-4683-7

[14] Lv, X., Ma, C., Fang, M. "Dynamic Analysis of a Shallow Buried Tunnel Influenced by a Neighboring Semi-cylindrical Hill and Semicylindrical Canyon", Periodica Polytechnica Civil Engineering, 63(3), pp. 804-811, 2019. https://doi.org/10.3311/PPci.14183

[15] Sánchez-Merino, A. L., Fernandez-Sáez, J., Navarro, C. "Simplified longitudinal seismic response of tunnels linings subjected to surface waves", Soil Dynamics and Earthquake Engineering, 29(3), pp. 579-582, 2009.

https://doi.org/10.1016/j.soildyn.2008.06.003

[16] Wang, Z. Z., Jiang, Y. J., Zhu, C. A. "Seismic energy response and damage evolution of tunnel lining structures", European Journal of Environmental and Civil Engineering, 23(6), pp. 758-770, 2019. https://doi.org/10.1080/19648189.2017.1304283

[17] Gomes, R. C. "Effect of stress disturbance induced by construction on the seismic response of shallow bored tunnels", Computers and Geotechnics, 49, pp. 338-351, 2013. https://doi.org/10.1016/j.compgeo.2012.09.007

[18] Mortezaei, A. "Plastic Hinge Length of RC Columns under the Combined Effect of Near-Fault Vertical and Horizontal Ground Motions", Periodica Polytechnica Civil Engineering, 58(3), pp. 243-253, 2014. https://doi.org/10.3311/PPci.7329

[19] Edinçliler, A., Toksoy, Y. S. "Shake Table Tests to Measure the Dynamic Performance of Geotextile-reinforced Embankment", Periodica Polytechnica Civil Engineering, 61(4), pp. 803-814, 2017. https://doi.org/10.3311/PPci.10540

[20] Haris, I., Farkas, G. "Experimental Results on Masonry Infilled RC Frames for Monotonic Increasing and Cyclic Lateral Load", Periodica Polytechnica Civil Engineering, 62(3), pp. 772-782, 2018. https://doi.org/10.3311/PPci.10715
[21] Kalitsov, A., Zermatten, P.-J., Bonell, F., Gaudin, G., Andrieu, S., Tiusan, C., Chshiev, M., Velev, J.-P. "Bias dependence of tunneling magnetoresistance in magnetic tunnel junctions with asymmetric barriers", Journal of Physics: Condensed Matter, 25, Article number: 496005, 2013.

https://doi.org/10.1088/0953-8984/25/49/496005

[22] Senent, S., Mollon, G., Jimenez, R. "Tunnel face stability in heavily fractured rock masses that follow the Hoek-Brown failure criterion", International Journal of Rock Mechanics and Mining Sciences, 60, pp. 440-451, 2013. https://doi.org/10.1016/j.ijrmms.2013.01.004

[23] Dai, F., Jiang, P., Xu, N., Chen, W., Tan, Y. "Focal mechanism determination for microseismic events and its application to the left bank slope of the Baihetan hydropower station in China", Environmental Earth Sciences, 77(7), Article number: 268, 2018. https://doi.org/10.1007/s12665-018-7443-1

[24] Dai, F., Li, B., Xu, N., Zhu, Y. "Microseismic early warning of surrounding rock mass deformation in the underground powerhouse of the Houziyan hydropower station, China", Tunnelling and Underground Space Technology, 62, pp. 64-74, 2017. https://doi.org/10.1016/j.tust.2016.11.009

[25] Wang, F., Jiang, X., Niu, J., Yang, H. "Experimental Study on Seismic Dynamic Characteristics of Shallow-Bias Tunnel with a Small Space", Shock and Vibration, 2018, Article number: 6412841, 2018. https://doi.org/10.1155/2018/6412841

[26] Yang, H., Jiang, X., Lian, P. "Seismic Response of Tunnel Lining for Shallow-Bias Tunnel with a Small Clear Distance under Wenchuan Earthquake", Advances in Civil Engineering, 2018, Article number: 2578062, 2018. https://oi.org/10.1155/2018/2578062

[27] Roateşi, S. "Analytical and numerical approach for tunnel face advance in a viscoplastic rock mass", International Journal of Rock Mechanics and Mining Sciences, 70, pp. 123-132, 2014. https://doi.org/10.1016/j.jijmms.2014.04.007

[28] Pinyol, N. M., Alonso, E. E. "Design of Micropiles for Tunnel Face Reinforcement: Undrained Upper Bound Solution", Journal of Geotechnical and Geoenvironmental Engineering, 138(1), pp. 89-99, 2012. https://doi.org/10.1061/(ASCE)GT.1943-5606.0000562

[29] Liu, X.-R., Li, D.-L., Wang, J.-B., Wang, Z. "Surrounding rock pressure of shallow-buried bilateral bias tunnels under earthquake", Geomechanics and Engineering, 9(4), pp. 427-445, 2015. https://doi.org/10.12989/gae.2015.9.4.427 